\title{
Disaster Psychological Rehabilitation by the Sustainable Development Approach in Iran
}

\author{
Mohammad Hassan Ehrampoush ${ }^{1}$, Abbas Ali Dehghani Tafti ${ }^{2}$, Farzaneh Aminharati ${ }^{3 *}$ iD
}

\begin{abstract}
${ }^{1}$ Department of Environmental Health Engineering, School of Public Health, Shahid Sadoughi University of Medical Sciences, Yazd, Iran ${ }^{2}$ Department of Disaster and Emergency Health, School of Public Health, Shahid Sadoughi University of Medical Sciences, Yazd, Iran ${ }^{3}$ Department of Pathobiology, School of Public Health, Tehran University of Medical Sciences, Tehran, Iran
\end{abstract}

\begin{tabular}{l} 
ARTICLE INFO \\
\hline \multicolumn{1}{c}{ COMMENTARY } \\
Article history: \\
Received: 1 Oct 2018 \\
Revised: 10 Jan 2019 \\
Accepted: 30 Jan 2019 \\
\hline
\end{tabular}

\section{* Corresponding Author:}

Farzaneh Aminharati

\section{Address:}

School of Public Health, Tehran University of Medical Sciences, Tehran, Iran

\section{Email:}

shahrood2005@yahoo.com

Tel:

$+983531492225$

$\mathrm{T}$ The concepts of sustainable development referred to global correlations between environmental problems with (social issues, economic poverty, inequalities), awareness and concerns about the future of human health. The most destructive natural and manmade hazards are damaging factors for communities and their environmental health. As well as incidents and conflicts are longtime history events of distasteful life phenomena that make to knees human and cause the geographic faces of many communities to change unexpectedly. Disaster impacts are death and millions of disabled people in the world each year, so the physical, mental and financial damages should be important to consider as a barrier to sustainable development of the communities $(1,2)$.

The role of disaster management is to minimize the adverse consequences of natural and manmade hazards at the level of society and natural resources by risk reduction activity, improving preparedness, timely response, preventing injuries, and recovery by sustainable development concepts. Although the creation of social capacity is not as important as structural shelter defenses and evacuation plans, the governments should focus on restoring physiological and social infrastructure by identifying the minimum measures after disasters. So with the same goal, disaster mental health management can develop in order to adopt unusual circumstances at the points of victims and rescuer views, and then overcome the community psychological challenges after adverse events. Therefore, the rare disorder population may enhance after disasters and communities are resilience to mental problems during and after unusual circumstances (3).

Understanding the complexity of the problems and the concepts of rehabilitation has an important role in effectively communicating during the rehabilitating programs. So the review of past collected data, detecting the statistical analyses related to rehabilitation services, and the opinions of relevant experience are required to investigate on vulnerable groups and why they are more vulnerable (4).

The core objectives of recovery programs after a 
disaster by the sustainable development goals are increasing resiliency, capacity-building priorities, developing justice and social /economic equality, and rehabilitating mental health programs in the survivor of a disaster. The first important step to reach these reality objectives is collecting cluster information that includes the national rehabilitation programs and carrying out some physiological disorders research on the post-traumatic stress disorder (PTSD) after the disaster. Moreover, the flexible multilateral objectives and stakeholder interventions should be considered during the process. To evaluate the rehabilitation programs after disasters, the appropriate items such as (planning, effectiveness toolset, training, intervention effects, feedback effectiveness measures, and continued flexibility changes) must be in a concept of community-based disaster management in the affected population (5).

The psychosocial rehabilitation programs that were carried out in Iran included the effectiveness of cognitive-behavioral therapy after the war in PTSD patients by Kashani in 2005, and Hashemian and Mirzaee in 2006 (6). The tools which were used in previous investigations for assessing the intervention impacts on different disaster exposures have been the General Health Questionnaire-28 (7), Rutter children's behavior questionnaire (8), and Watson PTSD interview $(9,10)$.

The investigation on war veteran life qualities by Najafi during 2011 revealed that the veterans who suffered from PTSD had serious mental health problems, bodily pain, weakness in general health and physical vitality functions, a low score in business and social functions (11).

Another study by Mirdoragi on veterans during 2012 which was about cognitive - behavioral inhibitions and (verbal/nonverbal) working memory showed the weaker neuropsychological symptoms that indicate a failure in cognitive- behavioral inhibition, and lack of sustained attention in working memory. Thus, the failure of such activity implementations can be the comprehensive definition of PTSD symptoms $(12,13)$.

The other studies cognitive-behavioral therapy has been more effective in reducing symptoms of stress disorder after the incident $(14,15)$. While in 2008, the studies by Farhoudian on the prevalence of PTSD showed the community-based interventions had been vital needs in the affected population (16).

The evidence showed that after Rudbar earthquake in 1990, the educational and investigating strategies in the preparedness program such as professional public manual series, training of trainer (TOT) workshop series have been established immediately by ( Yasamy et al., 2000 ) and then continued by relevant human resource development. Besides, a new series of professional training started for relief workers, and executive officers by the UNICEF support (15). Moreover, the Red Crescent relief worker educations have been provided the important training needs on basic psychosocial skills because they were the misinformed disaster survivors in the fatal happening of their close relatives in Qazvin earthquake. For this purpose, the mental health office in the ministry of health $(\mathrm{MOH})$ started the national programs with the cooperation of Red Crescent and Qazvin University of Medical Sciences in 2002 (15). In the same way, many interventions were conducted at the school and community, and training activities were implemented by $\mathrm{MOH}$ after Bam earthquake. However, Bam earthquake had 240 spinal cord injuries (SCI) and many patients, especially women feeling the fear of separation from their families, and the mental problems increased in earthquake victims. Therefore, the educational programs on $\mathrm{SCI}$ considered useful intervention and women have been enthusiastic in learning about their disabilities and more results of educational activities that appeared several months later (17).

To access sustainable development goals, the continuing rehabilitation programs are the most important strategies in order to develop human resources. By this means, TOTs were conducted by the ministry of health national disaster mental programs for Qazvin earthquake on June 22, 2002. Therefore, $\mathrm{MOH}$ was prepared for psychosocial interventions on the first following days of Bam devastating earthquake on December 26, 2003. 
Moreover, the trauma consulting programs for teachers have been placed directly by $\mathrm{MOH}$ and indirectly through trained professional school consultant (15). According to this, the communitybased psychosocial interventions in Iran was included the support of survivors, build up social networks, set up the public meetings by the psychosocial teams, employ the NGOs that participate in all stages of the program from planning to the operation, and more trained manpower in regional populations $(15,16)$.

For continual rehabilitation, monitoring program was done by the supervisors, and then feedbacks gave to field-mental health workers, so the effectiveness evaluation of programs was uninterrupted by collecting clinical data between the yearly field workers (18).

More studies showed that the permanence of psychosocial rehabilitation by the sustainable development approach can be achieved by providing the questioner checklist and assessing the indicators during three stages.

At the first stage, the established rehabilitation activities must be evaluated and promoted, while the empowerment flexibility should be promoted by the lifestyle improving.

During the second phase, capacity building and the assessment of needs should be conducted as a part of being secured and the resiliency rates of disaster victims should be evaluated. Therefore, the activated assessments use some of the social requirements such as dialogue, education, training, community feedback, and the appropriate social activities that should be implemented in various communities.

In the third round, technological capacity building assessments and opportunities for continuing rehabilitation must take place by the new

\section{References}

1.Davidson AC, Mellor DJ. The adjustment of children of Australian Vietnam veterans: is there evidence for the transgenerational transmission of the effects of warrelated trauma? Australian and New Zealand Journal of Psychiatry. 2001; 35(3): 345-51.

2. Renshaw KD, Rodrigues CS, Jones DH. Combat continuity employment ensuring. Therefore, reducing the stress and promoting the quality of life in people are very important issues that should be in essential objectives of health authorities in ensuring sustainable rehabilitation (19).

Today, learning communication skills such as conflict resolution training is one of the life skill activities in increasing educational awareness, by which the patient can be supported by their families. Thus, the community members will be able to improve their welfare by providing the new opportunities for consecutive monitoring (20).

These results improved that family health system attentions on PTSD patients may have been an important roles on educational policy plans, counseling, treatment, and the promotion of different communities which are the goals of sustainable development.

\section{Acknowledgments}

Thanks are owed to those whose experience were used in this study, and who cooperated in conducting this study: Azar Aminharati, and Farzaneh Sardari.

\section{Funding source}

There was no funding source for this study.

\section{Conflict of interest}

The authors did not report any conflict of interest.

\section{Authors' contribution}

Farzaneh Aminharati wrote the first draft of the manuscript. All authors read and approved the final draft of the manuscript.

exposure, psychological symptoms, and marital satisfaction in National Guard soldiers who served in Operation Iraqi Freedom from 2005 to 2006. Anxiety, Stress, \& Coping. 2009; 22(1): 101-15.

3. King DW, Taft C, King LA, et al. Directionality of the association between social support and Posttraumatic 
Stress Disorder: A longitudinal investigation 1. Journal of Applied Social Psychology. 2006; 36(12): 2980-92.

4. Tang B, Deng Q, Glik D, et al. A meta-analysis of risk factors for post-traumatic stress disorder (PTSD) in adults and children after earthquakes. International journal of environmental research and public health. 2017; 14(12): 1537.

5. Watson PJ, Brymer MJ, Bonanno GA. Postdisaster psychological intervention since 9/11. American Psychologist. 2011; 66(6): 482.

6. Mirzamani SM, Karaminia R, Azad-Marzabadi E, et al. Being a wife of a veteran with psychiatric problem or chemical warfare exposure: A preliminary report from Iran. Iranian journal of psychiatry. 2006; 1(2): 65-9.

7. Makvand Hosseini S, Kasiri M, Najafi M, et al. Effectiveness of Cognitive-Behavior Therapy on Mental Health of PTSD Veterans under Pharmaceutical Treatment. Iranian Journal of War and Public Health. 2015; 7(2): 67-72.

8. Mohammadinia L, Khorasani-Zavareh D, Ebadi A, et al. Characteristics and components of children's and adolescents' resilience in disasters in Iran: a qualitative study. International Journal of Qualitative Studies on Health and Well-being. 2018; 13(sup1): 1479584.

9. Roudini J, Khankeh H, Witruk E, et al. Community Mental Health Preparedness in Disasters: A Qualitative Content Analysis in an Iranian Context. Health in Emergencies and Disasters Quarterly. 2017; 2 (4): 165178.

10. Askari A, Rowell RK, Alipour F. Prevalence of psychopathology and socio- demographic characteristics among earthquake survivors in Eastern Azerbaijan, Iran. Health in Emergencies and Disasters. 2015; 1(1): 9-15.

11. Rahnejat A, Dabagi P, Rabiei M, et al. Prevalence of Post-Traumatic Stress Disorder Caused by War in Veterans. Iran J War Public Health. 2017; 9(1): 15-23.

12. Rahnejat AM, Rabiei M, Salimi SH, et al. Causal Metacognitive Model War-related Chronic
Posttraumatic Stress Disorder. Iranian Journal of Psychiatry and Clinical Psychology. 2015;20(4):317325.

13. Mirdoraghi F, Hashemabady G, Mashhadi A. Cognitive and behavioral inhibition in veterans withand without post traumatic stress disorder. Journal Mil Med. 2012; 14(1): 41-7.

14. Azad EM, Hashemi SZ. The Effectiveness of Mindfulness Training in Improving the Quality of Life of the War Victims with Post Traumatic stress disorder (PTSD). Iranian journal of psychiatry. 2014; 9(4): 22836.

15. Yasamy M, Farajpour M, Gudarzi S, et al. Disaster mental health care in Iran: responses based on needs.In: Prewitt Diaz OJ, Murthy SR, Lakshminarayana R editors. Advances in disaster mental health and psychological support. NewDelhi: Voluntary Health Association of India Press; 2006. P: 61-8.

16. Farhoudian A, Hajebi A, Bahramnejad A, et al. The perspective of psychosocial support a decade after Bam earthquake: Achievements and challenges. Psychiatric Clinics. 2013;36(3):385-402.

17. Raissi GR. Earthquakes and rehabilitation needs: experiences from Bam, Iran. The journal of spinal cord medicine. 2007; 30(4): 369-72.

18. Ardalan A, Sohmbizadeh S, Latifi $M$, et al. Responding to physical and psychological health impacts of disasters: case study of the Iranian disaster rehabilitation plan. EMHJ-Eastern Mediterranean Health Journal. 2016; 22(3): 212-8.

19. Shaw R, Gupta M, Sarma A. Community recovery and its sustainability: Lessons from Gujarat earthquake of India. Australian Journal of Emergency Management, The. 2003; 18(2): 28.

20. Sayers SL, Farrow VA, Ross J, et al. Family problems among recently returned military veterans referred for a mental health evaluation. Journal of Clinical Psychiatry. 2009; 70(2): 163. 